\title{
Uji Efektivitas Berbagai Konsentrasi Pestisida Nabati Bintaro (Cerbera manghas) terhadap Hama Ulat Grayak (Spodoptera litura) pada Tanaman Kedelai
}

DOI 10.18196/pt.2014.029.99-105

\author{
Agus Nugroho Setiawan* dan Achmad Supriyadi \\ Program Studi Agroteknologi, Fakultas Pertanian, Universitas Muhammadiyah Yogyakarta, \\ Jl. Lingkar Selatan, Kasihan, Bantul, Yogyakarta 55183, Indonesia Telp. 0274387656 , \\ *Corresponding author: agus_enes@yahoo.com
}

\begin{abstract}
ABSTRAK
Ulat grayak (Spodoptera litura) merupakan salah satu hama utama dalam budidaya tanaman kedelai yang dapat menyebabkan kerusakan hingga 80\%. Salah satu bentuk pengendalian yang dilakukan yaitu dengan memanfaatkan tanaman bintaro (Cerbera odollam) yang berpotensi sebagai pestisida (insektisida) nabati. Penelitian ini bertujuan untuk mengetahui efektivitas ekstrak bintaro sebagai pestisida nabati dan mendapatkan konsentrasi ekstrak buah, daun muda, dan daun tua bintaro yang tepat untuk mengendalikan ulat grayak pada tanaman kedelai, serta pengaruhnya terhadap pertumbuhan tanaman kedelai. Penelitian ini menggunakan metode eksperimen yang didesain dalam Rancangan Acak Lengkap faktor tunggal menggunakan pestisida Bintaro (daun muda, daun tua, dan buah), yang terdiri dari tiga konsentrasi (100 g/l, $200 \mathrm{~g} / \mathrm{l}$, dan $300 \mathrm{~g} / \mathrm{ll}$ ), ditambah dua perlakuan yaitu, disemprot dengan air dan larutan pestisida sintetis sebagai kontrol. Hasil penelitian menunjukkan daun dan buah Bintaro pada konsentrasi 100 - 300 g/l dengan cara ekstraksi menggunakan pelarut air, belum efektif digunakan sebagai pestisida nabati untuk mengendalikan hama ulat Spodoptera litura pada tanaman kedelai. Ekstrak daun tua Bintaro (100 g/l) menghasilkan nilai mortalitas dan kecepatan kematian hama tertinggi sebesar 40,00\% dan 2,00. Penggunaan ekstrak daun dan buah Bintaro sebagai pestisida nabati tidak menghambat pertumbuhan tanaman kedelai.

Kata kunci: Ekstrak bintaro, Pestisida nabati, Kedelai, Mortalitas, Spodoptera litura
\end{abstract}

\begin{abstract}
Spodoptera litura is a major pest in soybean cultivation causing damage by 80\%. One of control is done by using bintaro plants (Cerbera manghas) potential as a botanical pesticide (insecticide). This study aims to determine the effectiveness of botanical pesticide from bintaro extract and get the precise extract concentration of fruit, young leaves, and old leaves of bintaro to control Spodoptera litura on soybean plants, and its influence to the growth of soybean plants. This study used an experimental method that is designed in a single factor completely randomized design using pesticides Bintaro (young leaves, old leaves, and fruit), which consists of three concentrations (100 g / l, $200 \mathrm{~g} / \mathrm{l}$, and $300 \mathrm{~g} / \mathrm{l})$, add two treatments, namely, sprayed with water and a synthetic pesticides as a control. Result showed the leaves and fruit of Bintaro at concentrations of $100 \mathrm{~g} /$ I to $300 \mathrm{~g} /$ I by solvent extraction has not been effectively used as botanical pesticide to control Spodoptera litura on soybean plants. Old leaf Bintaro extract (100 g/I) produces highest pest mortality value and rate of $40.00 \%$ and 2.00. The use of botanical pesticide from extract bintaro (fruit and leaf) is not inhibit the growth of soybean plants. Keywords: Extract of Bintaro leaf, Organic Pesticides, Soybean, Mortality, Spodoptera litura
\end{abstract}

\section{PENDAHULUAN}

Kedelai merupakan salah satu komoditas pertanian yang sangat dibutuhkan di Indonesia, bahkan dalam tatanan perdagangan internasional, kedelai menjadi komoditas eksport olahan berupa minyak nabati, pakan ternak dan lain lain di berbagai negara di dunia (Rukmana, 1996). Namun, produktivitas kedelai dalam negeri hingga saat ini belum mampu mencukupi kebutuhan. Rerata kebutuhan kedelai secara nasional mencapai 2,2 juta ton/ th, sedangkan produksi dalam negeri baru memenuhi $20-30 \%$ dari kebutuhan tersebut. 70-80\% kekurangannya dipenuhi dari impor. (Purna, 2009).

Salah satu ancaman dalam upaya meningkatkan produksi kedelai adalah serangan hama. Serangga yang berasosiasi dengan tanaman kedelai di Indonesia mencapai 266 jenis (Okada et al. 1988 dalam Marwoto dan Suharsono, 2011). Dari 111 jenis serangga hama tersebut, 50 jenis tergolong hama perusak daun, salah satunya adalah ulat grayak (Spodoptera litura) (Arifin dan Sunihardi, 1997). Kehilangan hasil akibat 
serangan hama tersebut dapat mencapai 80\%, bahkan puso jika tidak dikendalikan. Usaha pengendalian hama di tingkat petani hingga kini masih mengandalkan insektisida sintetis, namun terkendala biaya yang mahal dan adanya resistensi hama. Untuk itu, digunakan pestisida nabati berbahan Bintaro yang menurut Tarmadi dkk (1997), menghasilkan metabolit sekunder seperti saponin, polifenol, dan tanin. Zat-zat ini memiliki potensi dimanfaatkan sebagai pestisida untuk mengendalikan hama pada tanaman secara efektif dan ramah lingkungan. Pemanfaatan Bintaro sebagai bahan pestisida masih belum dikenal secara umum, sehingga perlu penelitian untuk mengetahui pengaruh ekstrak bintaro sebagai pestisida nabati dalam mengendalikan hama Ulat Grayak (Spodoptera litura) pada tanaman kedelai.

Penelitian ini bertujuan untuk mengetahui efektivitas ekstrak bintaro sebagai pestisida nabati dan mendapatkan konsentrasi ekstrak buah, daun muda, dan daun tua Bintaro yang tepat untuk mengendalikan ulat grayak pada tanaman kedelai, serta pengaruhnya terhadap pertumbuhan tanaman kedelai.

\section{BAHAN DAN METODE}

Bahan yang digunakan dalam penelitian ini adalah buah dan daun Bintaro, benih kedelai, daun tanaman kedelai yang berumur 28-35 HST, ulat grayak instar 3, pupuk SP-36, alkohol 70\%, bahan perekat (sticker) dan air. Alat yang digunakan adalah blender, gelas ukur, kain tile, pipet ukur, blender, corong, polybag, gunting, penggaris, timbangan elektrik, hand sprayer, pinset, kertas label.

Penelitian dilakukan menggunakan metode eksperimen yang didesain dalam Rancangan Acak Lengkap faktor tunggal menggunakan pestisida Bintaro (daun muda, daun tua, dan buah), yang terdiri dari tiga konsentrasi (100 gr/1, 200 $\mathrm{gr} / \mathrm{l}$, dan $300 \mathrm{~g} / \mathrm{l}$ ), ditambah dua perlakuan, disemprot dengan air dan larutan pestisida sintetis sebagai kontrol. Setiap perlakuan diulang sebanyak 3 kali.

Pengamatan dilakukan untuk mengetahui pengaruh toksisitas ekstrak bintaro terhadap hama maupun tanaman kedelai. Adapun parameter pengamatannya yaitu:

\section{Mortalitas}

Penghitungan persentase mortalitas menggunakan rumus sebagai berikut:

$$
\mathrm{M}=\frac{b}{a+b} \times 100 \%
$$

(Fagoone dan Lauge, 1981 dalam Sinaga, 2009)

Keterangan: $\mathrm{M}$ = Persentase Mortalitas hama; $\mathrm{a}=$ Jumlah Spodoptera litura yang mati; $\mathrm{b}=$ Jumlah Spodoptera litura yang hidup.

\section{Kecepatan Kematian}

$$
\text { Rumus: } \mathrm{V}=\frac{T 1 N 1+T 2 N 2+T 3 N 3+\cdots T n N n}{n}
$$

Keterangan: $\mathrm{V}=$ Kecepatan kematian; $\mathrm{T}=$ Waktu pengamatan; $\mathrm{N}=$ Jumlah serangga yang mati; $\mathrm{n}=$ Jumlah serangga yang diujikan

\section{Penurunan Aktivitas Makan}

Pengamatan dimulai dengan menimbang bobot pakan (daun kedelai) yang habis dimakan serangga uji pada periode 1-7 HSA. Variabel ini digunakan untuk mengetahui tingkat palatabilitas ulat grayak yang diamati berdasarkan tingkat penurunan persentase aktivitas makan.

Persentase penurunan aktivitas makan dihitung dengan rumus sebagai berikut:

$$
\mathrm{P}=1-(\mathrm{T} / \mathrm{C}) \times 100 \%
$$

(Pujiono, 1988 dalam Tohir 2010) 
Keterangan: $\mathrm{P}=$ persentase penurunan aktivitas makan; $\mathrm{T}=$ bobot pakan yang dimakan dari perlakuan; $\mathrm{C}=$ bobot pakan yang dimakan dari kontrol

\section{Intensitas Serangan}

Variabel pengamatan berikutnya adalah kategori skala kerusakan pada daun/ tanaman yang didasarkan pada pengamatan secara kualitatif yang selanjutnya dibuat nilai skala (skoring). Angka skoring ini akan digunakan untuk menghitung intensitas serangan hama Spodoptera litura melalui rumus sebagai berikut:

$$
\text { IS }=\frac{\sum(\mathrm{n} \times \mathrm{v})}{\mathrm{Z} \times \mathrm{N}} \times 100 \%
$$

Keterangan: IS : Intensitas Serangan; $\mathrm{n}$ : jumlah daun rusak tiap kategori serangan; $\mathrm{v}$ : nilai skala tiap kategori serangan; Z : Nilai skala tertinggi kategori serangan; $\mathrm{N}$ : Jumlah daun yang diamati

Sedangkan nilai skala yang digunakan, dikategorikan sebagai berikut:

0 : tidak terdapat kerusakan pada daun

1 : terdapat kerusakan dari $0-20 \%$

3 : terdapat kerusakan dari $20-40 \%$

5 : terdapat kerusakan dari $40-60 \%$

7 : terdapat kerusakan dari $60-80 \%$

9 : terdapat kerusakan lebih dari $80 \%$

Kemudian variabel jumlah hama yang mati setelah perlakuan pestisida nabati digunakan untuk menghitung mortalitas dan kecepatan kematian. Pengamatan dilakukan setiap hari setelah satu hari aplikasi selama 7 hari.

\section{Tinggi Tanaman $(\mathrm{cm})$}

Tinggi tanaman diamati setiap satu minggu sekali, dengan cara mengukur tinggi tanaman (batang primer) dari permukaan tanah sampai dengan titik tumbuh.

\section{Jumlah Daun}

Jumlah daun diamati setiap satu minggu sekali, mulai umur 7 hst sampai 49 hst.. pengamatan dengan menghitung jumlah daun yang telah terbuka dan hijau.

\section{Biomassa/ Berat Kering}

Pengamatan dilakukan sebanyak 3 kali sepanjang masa tanam dengan cara mencabut tanaman dan dikering anginkan kemudian dikeringkan menggunakan oven pada suhu 80 derajat dan ditimbang hingga mencapai berat konstans. Pengukuran biomassa/ berat kering tanaman pada tanaman korban setiap 2 minggu sekali. Analisis Data

Data hasil pengamatan selanjutnya dianalisis menggunakan sidik ragam pada jenjang 5\%, apabila ada pengaruh nyata dilakukan uji lanjut menggunakan uji jarak berganda Duncan pada jenjang $5 \%$.

\section{HASIL DAN PEMBAHASAN}

Mortalitas dan Kecepatan Kematian

Hasil analisis sidik ragam menunjukkan bahwa perlakuan ekstrak Bintaro tidak berpengaruh nyata terhadap mortalitas maupun kecepatan kematian hama (Tabel 1). Hal ini dapat disebabkan oleh konsentrasi senyawa aktif pada bahan yang rendah. Selain itu, metode ekstraksi yang digunakan tidak mampu melarutkan senyawa aktif pada bahan secara optimal.

Hasil penelitian menunjukkan bahwa senyawa aktif di antaranya saponin, polifenol dan tanin yang terkandung pada ekstrak bintaro diduga mampu meracuni dan menghambat metabolisme hama, hingga menyebabkan kematian hama. Hal ini didukung dengan penelitian Utami, 
(2010), menunjukkan bahwa ekstrak biji, buah dan daun Bintaro pada kadar terendah 0,125\% dengan pelarut murni methanol, mengakibatkan mortalitas larva Eurema spp. sebesar 36,67\%.

Tabel 1. Mortalitas dan Kecepatan Kematian Hama Ulat Spodoptera litura pada Berbagai Perlakuan Ekstrak Bintaro

\begin{tabular}{lcc}
\hline \multicolumn{1}{c}{ Perlakuan } & Mortalitas (\%) & Kecepatan Kematian \\
\hline Ekstrak daun muda Bintaro, konsentrasi $100 \mathrm{~g} / \mathrm{I}$ & 16,67 & 1,17 \\
Ekstrak daun muda Bintaro, konsentrasi $200 \mathrm{~g} / \mathrm{I}$ & 16,67 & 1,10 \\
Ekstrak daun muda Bintaro, konsentrasi $300 \mathrm{~g} / \mathrm{I}$ & 13,33 & 0,70 \\
Ekstrak daun tua Bintaro, konsentrasi $100 \mathrm{~g} / \mathrm{I}$ & 40,00 & 2,00 \\
Ekstrak daun tua Bintaro, konsentrasi $200 \mathrm{~g} / \mathrm{I}$ & 20,00 & 1,10 \\
Ekstrak daun tua Bintaro, konsentrasi $300 \mathrm{~g} / \mathrm{I}$ & 23,33 & 1,47 \\
Ekstrak buah Bintaro, konsentrasi $100 \mathrm{~g} / \mathrm{I}$ & 10,00 & 0,57 \\
Ekstrak buah Bintaro, konsentrasi $200 \mathrm{~g} / \mathrm{I}$ & 3,33 & 0,23 \\
Ekstrak buah Bintaro, konsentrasi $300 \mathrm{~g} / \mathrm{I}$ & 33,33 & 1,97 \\
Pestisida sintesis (sihalotrin) & 46,67 & 2,033 \\
Kontrol air & 0,00 & 0,00 \\
\hline
\end{tabular}

Keterangan: Angka yang diikuti huruf yang sama tidak menunjukkan pengaruh nyata pada jenjang $5 \%$ berdasarkan uji jarak berganda Duncan.

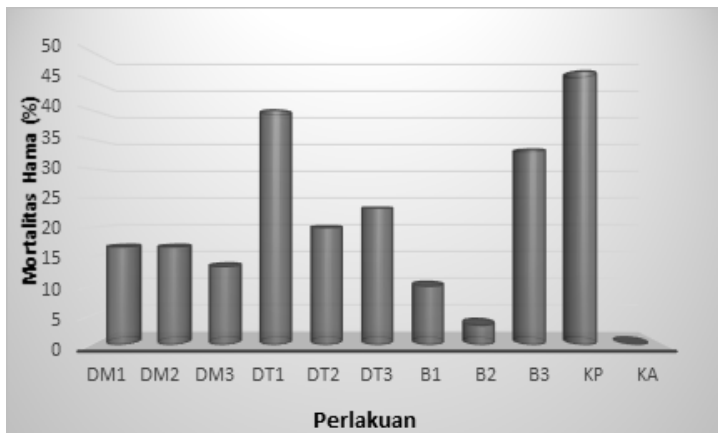

Gambar 1. Mortalitas Hama Ulat Spodoptera litura pada Berbagai Perlakuan Ekstrak Bintaro

\footnotetext{
Keterangan:

DM1 = Daun muda Bintaro $100 \mathrm{~g} / \mathrm{l}$

DM2 = Daun muda Bintaro $200 \mathrm{~g} / \mathrm{l}$
DM3 = Daun muda Bintaro $300 \mathrm{~g} / \mathrm{l}$

DM3 = Daun muda Bintaro $300 \mathrm{~g} /$
DT1 = Daun tua Bintaro $100 \mathrm{~g} / \mathrm{l}$

DT2 = Daun tua Bintaro $200 \mathrm{~g} / \mathrm{l}$

DT3 = Daun tua Bintaro $300 \mathrm{~g} / \mathrm{l}$
}

$$
\begin{aligned}
& \mathrm{B} 1=\text { Buah Bintaro } 100 \mathrm{~g} / \mathrm{l} \\
& \mathrm{B} 2=\text { Buah Bintaro } 200 \mathrm{~g} / \mathrm{l} \\
& \mathrm{B} 3=\text { Buah Bintaro } 300 \mathrm{~g} / \mathrm{l} \\
& \mathrm{KP}=\text { Pestisida Sintesis } \\
& \mathrm{KA}=\text { Kontrol air }
\end{aligned}
$$

Kecepatan kematian menunjukkan jumlah ulat yang mati dalam satuan waktu tertentu. Indeks nilai kecepatan kematian tertinggi pada perlakuan ekstrak daun tua Bintaro sebesar 2, hal ini tidak berbeda jauh jika dibandingkan dengan kontrol pestisida sintesis yang hanya 2,033 (Gambar 2). Selanjutnya diikuti oleh perlakuan ekstrak buah Bintaro dengan nilai tertinggi 1,967. Kematian larva berlangsung relatif lambat dalam hitungan hari, karena kematian paling banyak terjadi pada hari ke-4 dan 5 untuk perlakuan daun tua bintaro. Hal ini dimungkinkan kadar senyawa aktif yang rendah hingga menyebabkan reaksi pestisida Bintaro yang lambat dalam menghambat aktivitas hama.

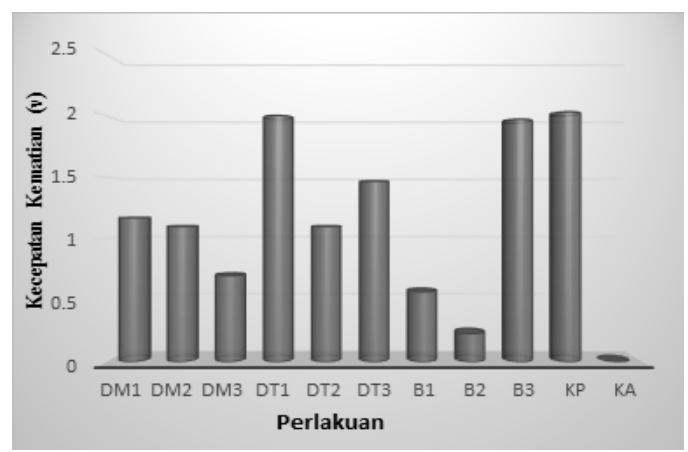

Gambar 2. Kecepatan Kematian Hama Ulat Spodoptera litura pada Berbagai Perlakuan Ekstrak Bintaro

Keterangan:

DM1 = Daun muda Bintaro $100 \mathrm{~g}$

DM2 = Daun muda Bintaro $200 \mathrm{~g} /$

DM3 = Daun muda Bintaro $300 \mathrm{~g} /$

DT1 = Daun tua Bintaro $100 \mathrm{~g} /$

DT2 = Daun tua Bintaro $200 \mathrm{~g}$

DT3 = Daun tua Bintaro $300 \mathrm{~g} / \mathrm{l}$

$$
\begin{aligned}
& \text { B1 = Buah Bintaro } 100 \mathrm{~g} / \mathrm{l} \\
& \text { B2 }=\text { Buah Bintaro } 200 \mathrm{~g} / \mathrm{l} \\
& \text { B3 }=\text { Buah Bintaro } 300 \mathrm{~g} / \mathrm{l} \\
& \text { KP }=\text { Pestisida Sintesis } \\
& \text { KA = Kontrol air }
\end{aligned}
$$

Penurunan Aktivitas Makan (Tingkat Palatabilitas)

\section{Hama Spodoptera litura}

Palatabilitas menggambarkan aktivitas makan hama setelah perlakuan, ditandai dengan bobot daun yang habis dimakan ulat, untuk selanjutnya dibandingkan dengan bobot daun kontrol. Perubahan bobot pakan ditimbang setiap harinya, rentang 1-7 hari setelah tanam. Data bobot pakan harian yang diperoleh selanjutnya digunakan untuk menghitung dan mengamati palatabilitas ulat grayak berdasarkan tingkat penurunan persentase aktivitas makan serangga harian. Tabel 2 memberikan gambaran besarnya persentase penurunan aktivitas makan hama selama pengamatan pada 1-7 hari setelah aplikasi.

Perlakuan ekstrak daun tua Bintaro (100 g/l) dapat menurunkan aktivitas makan hama hingga 
$43 \%$, diikuti oleh ekstrak daun muda Bintaro $(300 \mathrm{~g} / \mathrm{l})$ dan ekstrak daun tua Bintaro (200 $\mathrm{g} / \mathrm{l})$ berturut turut sebesar $14,1 \%$ dan $1,37 \%$. Aktivitas makan hama pada kontrol pestisida berkurang karena pengaruh pestisida sintesis juga sebagai antifeedant. Pada perlakuan ekstrak bintaro diduga memiliki peran yang sama. Pakan yang mengandung ekstrak mampu meracuni tanaman, sehingga menurunkan aktivitas makan hama. Hal ini menunjukkan bahwa ekstrak bintaro, terutama daun tua Bintaro selain berpotensi menyebabkan mortalitas juga menurunkan palatabilitas makan hama.

Tabel 2. Persentase Penurunan Aktivitas Makan Ulat Grayak (Spodoptera litura) pada Perlakuan Ekstrak bintaro

\begin{tabular}{lc}
\hline \multicolumn{1}{c}{ Perlakuan } & Penurunan Aktivitas Makan (\%) \\
\hline Ekstrak daun muda Bintaro, konsentrasi $100 \mathrm{~g} / \mathrm{I}$ & -22 \\
Ekstrak daun muda Bintaro, konsentrasi $200 \mathrm{~g} / \mathrm{I}$ & $-6,6$ \\
Ekstrak daun muda Bintaro, konsentrasi $300 \mathrm{~g} / \mathrm{I}$ & 14,1 \\
Ekstrak daun tua Bintaro, konsentrasi $100 \mathrm{~g} / \mathrm{I}$ & 43 \\
Ekstrak daun tua Bintaro, konsentrasi $200 \mathrm{~g} / \mathrm{I}$ & 1,37 \\
Ekstrak daun tua Bintaro, konsentrasi $300 \mathrm{~g} / \mathrm{I}$ & $-3,1$ \\
Ekstrak buah Bintaro, konsentrasi $100 \mathrm{~g} / \mathrm{I}$ & -12 \\
Ekstrak buah Bintaro, konsentrasi $200 \mathrm{~g} / \mathrm{I}$ & $-9,8$ \\
Ekstrak buah Bintaro, konsentrasi $300 \mathrm{~g} / \mathrm{I}$ & $-2,9$ \\
Pestisida sintesis (sihalotrin) & 59,6 \\
Kontrol air & 0 \\
\hline
\end{tabular}

Pengaruh Ekstrak bintaro Terhadap Pertumbuhan Tanaman Kedelai

Tabel 3 menunjukkan bahwa perlakuan ekstrak bintaro tidak berpengaruh negatif terhadap tinggi tanaman dan jumlah daun kedelai. Perlakuan ekstrak bintaro terhadap tanaman tidak menghambat pertumbuhan tanaman. Hal ini karena bahan aktif yang terkandung dalam ekstrak bintaro lebih bereaksi dalam menghambat aktivitas hama, sehingga relatif aman bagi pertumbuhan tanaman. Pengaruh perlakuan Bintaro terhadap pertumbuhan tanaman kedelai dapat dilihat pada Gambar 3 dan 4.
Tabel 3. Tinggi Tanaman dan Jumlah Daun Tanaman Kedelai pada Hari ke- 7

\begin{tabular}{lcc}
\hline \multicolumn{1}{c}{ Perlakuan } & $\begin{array}{c}\text { Tinggi Tanaman } \\
(\mathrm{cm})\end{array}$ & $\begin{array}{c}\text { Jumlah Daun } \\
\text { (helai) }\end{array}$ \\
\hline Ekstrak daun muda Bintaro, konsentrasi $100 \mathrm{~g} / \mathrm{I}$ & $115,53 \mathrm{ab}$ & $21,00 \mathrm{abc}$ \\
Ekstrak daun muda Bintaro, konsentrasi $200 \mathrm{~g} / \mathrm{I}$ & $119,40 \mathrm{ab}$ & $25,33 \mathrm{abc}$ \\
Ekstrak daun muda Bintaro, konsentrasi $300 \mathrm{~g} / \mathrm{I}$ & $87,70 \mathrm{~d}$ & $15,33 \mathrm{c}$ \\
Ekstrak daun tua Bintaro, konsentrasi $100 \mathrm{~g} / \mathrm{I}$ & $115,40 \mathrm{ab}$ & $30,00 \mathrm{a}$ \\
Ekstrak daun tua Bintaro, konsentrasi $200 \mathrm{~g} / \mathrm{I}$ & $114,57 \mathrm{ab}$ & $25,33 \mathrm{abc}$ \\
Ekstrak daun tua Bintaro, konsentrasi $300 \mathrm{~g} / \mathrm{I}$ & $93,83 \mathrm{dc}$ & $19,33 \mathrm{bc}$ \\
Ekstrak buah Bintaro, konsentrasi $100 \mathrm{~g} / \mathrm{I}$ & $112,63 \mathrm{abc}$ & $21,67 \mathrm{abc}$ \\
Ekstrak buah Bintaro, konsentrasi $200 \mathrm{~g} / \mathrm{I}$ & $105,10 \mathrm{bcd}$ & $25,00 \mathrm{abc}$ \\
Ekstrak buah Bintaro, konsentrasi $300 \mathrm{~g} / \mathrm{I}$ & $110,87 \mathrm{abc}$ & $21,67 \mathrm{abc}$ \\
Pestisida sintesis (Sihalotrin) & $126,47 \mathrm{a}$ & $27,33 \mathrm{ab}$ \\
Kontrol air & $122,87 \mathrm{ab}$ & $27,33 \mathrm{ab}$ \\
\hline
\end{tabular}

Keterangan: Angka yang diikuti huruf yang sama tidak menunjukkan pengaruh nyata pada jenjang $5 \%$ berdasarkan uji jarak berganda Duncan.

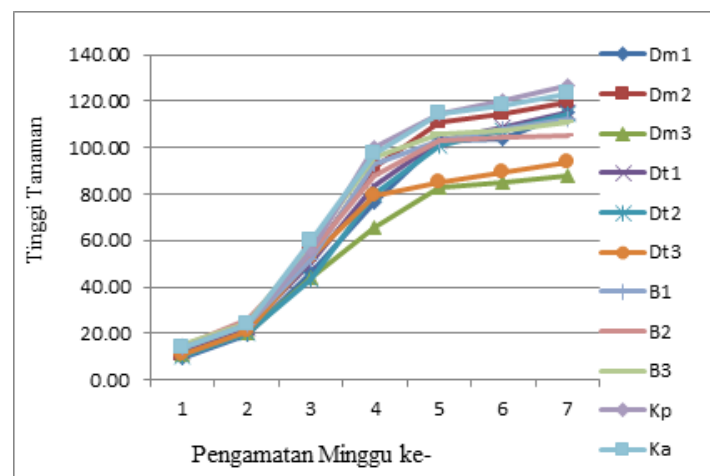

Gambar 3. Tinggi Tanaman Kedelai pada Berbagai Ekstrak Bintaro

=Daun muda Bintaro $100 \mathrm{~g} /$

DM2 = Daun muda Bintaro $200 \mathrm{~g} /$

DM3 = Daun muda Bintaro $300 \mathrm{~g} / \mathrm{l}$

DT1 = Daun tua Bintaro $100 \mathrm{~g} /$

DT2 = Daun tua Bintaro $200 \mathrm{~g} /$

DT3 = Daun tua Bintaro $300 \mathrm{~g} /$

$$
\begin{aligned}
& \text { B1 }=\text { Buah Bintaro } 100 \mathrm{~g} / \mathrm{l} \\
& \text { B2 }=\text { Buah Bintaro } 200 \mathrm{~g} / \mathrm{l} \\
& \text { B3 }=\text { Buah Bintaro } 300 \mathrm{~g} / \mathrm{l} \\
& \mathrm{KP}=\text { Pestisida Sintesis } \\
& \mathrm{KA}=\text { Kontrol air }
\end{aligned}
$$

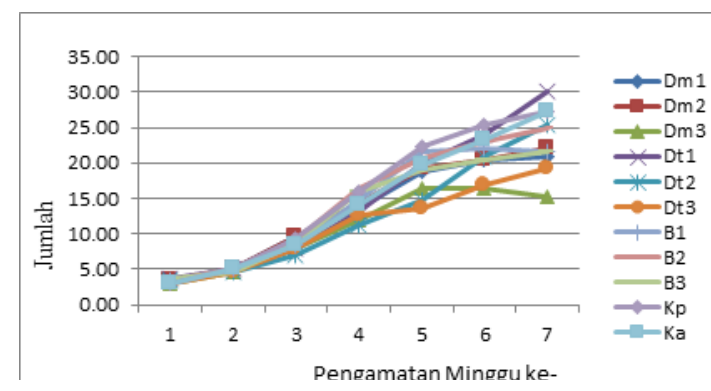

Gambar 4. Jumlah Daun Tanaman Kedelai pada Berbagai Ekstrak Bintaro

Keterangan:

DM1 = Daun muda Bintaro $100 \mathrm{~g} /$ DM2 = Daun muda Bintaro $200 \mathrm{~g} /$

DM3 = Daun muda Bintaro $300 \mathrm{~g}$

DT1 = Daun tua Bintaro $100 \mathrm{~g} / \mathrm{l}$

DT2 = Daun tua Bintaro $200 \mathrm{~g} /$

DT3 = Daun tua Bintaro $300 \mathrm{~g} / \mathrm{l}$

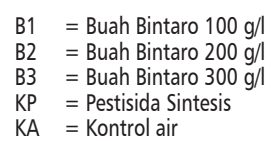

B1 = Buah Bintaro $100 \mathrm{~g} /$

B2 = Buah Bintaro $200 \mathrm{~g} / \mathrm{l}$

B3 = Buah Bintaro $300 \mathrm{~g} / \mathrm{l}$

$\mathrm{KP}=$ Pestisida Sintesis

$\mathrm{KA}=$ Kontrol air 
tanaman terdapat senyawa metabolit primer dan sekunder. Senyawa metabolit sekunder yang adalah senyawa kimia tumbuhan yang tidak secara universal ditemukan pada semua tumbuhan tingkat tinggi, tapi terbatas pada taksa tumbuhan tertentu dengan konsentrasi tertentu. Senyawa metabolit sekunder ini tidak terlalu berperan penting dalam proses pertumbuhan dan perkembangan tumbuhan, namun terdapat variasi dan jumlah metabolit sekunder tumbuhan yang besar. Contoh senyawa sekunder adalah flavonoid, terpenoid dan alkaloid yang melindungi tanaman dari serangan hama dan penyakit (Dadang \& Prijono, 2008 dalam Utami, 2010).

Tanaman Bintaro pun mengandung beberapa senyawa metabolit sekunder. Menurut Shaleh (1997) dalam Tarmadi dkk (1997), pada daun, buah dan kulit batang mengandung saponin, daun dan buahnya juga mengandung polifenol, disamping itu kulit batangnya mengandung tanin. Selain itu, juga terdapat cerberin yang bersifat digoxin atau racun yang mengganggu fungsi saluran ion kalsium ke dalam otot jantung. Senyawa saponin, polifenol, dan tanin, memiliki efek toksik bagi hama (bersifat insektisidal).

\section{SIMPULAN}

Berdasarkan hasil penelitian yang diperoleh, maka dapat diambil kesimpulan bahwa daun dan buah Bintaro pada konsentrasi 100 - 300 g/ 1 dengan cara ekstraksi menggunakan pelarut air, belum efektif digunakan sebagai pestisida nabati untuk mengendalikan hama ulat Spodoptera litura pada tanaman kedelai. Nilai mortalitas dan kecepatan kematian hama tertinggi diperoleh pada perlakuan ekstrak daun tua Bintaro (100 g/l) dengan nilai berturut- turut 40,00\% dan 2, 00. Penggunaan ekstrak daun dan buah bintaro tidak menghambat pertumbuhan tanaman kedelai.
Perlu dilakukan penelitian lanjutan menggunakan Bintaro dengan konsentrasi yang lebih tinggi untuk mendapatkan konsentrasi yang tepat dan efektif digunakan dalam mengendalikan hama Spodoptera litura. Metode ektraksi perlu diperbaiki baik dari bahan pelarut maupun teknik ekstraksi, sehinngga konsentrasi senyawa aktif yang dihasilkan lebih tinggi.

\section{DAFTAR PUSTAKA}

Kardinan. 2002. Pestisida Nabati, Ramuan Dan Aplikasinya. Penebar Swadaya. Jakarta.

Kastono, D. 2005. Tanggapan Pertumbuhan dan Hasil Kedelai Hitam Terhadap Penggunaan Pupuk Organik dan Biopestisida Gulma Siam (Chromolaena Odorata). Ilmu Pertanian Vol. 12 (2) : $103-116$

Mulyani. 2007. Bioprospek Cerbera odollam Gaertn., Croton tiglium L. dan Jatropha curcas L. Sebagai Bahan Baku Biodiesel. Undergraduate Theses dari JBPTITBBI.

Nursiam, I. 2010. Saponin. Laporan Praktikum Fakultas Peternakan IPB. Bogor. http://intannursiam.wordpress. com/2010/07/06/laporan-ipn-3-tan-saponin/ (diakses pada 6 Juli 2012)

Pracaya. 2009. Hama dan Penyakit Tanaman. Penebar Swadaya. Jakarta.

Purna, I. dkk. 2009. Upaya Peningkatan Produksi Kedelai http:// www.setneg.go.id/index.php?option=com_content\&task=vie w\&id=3761\&ltemid=29 (Diakses pada 25 Januari 2012).

Purwono dan H. Purnamawati. 2009. Budidaya 8 Jenis Tanaman Pangan Unggul. Penebar Swadaya. Jakarta.

Rukmana, R dan Y. Yuniarsih. 1996. Kedelai. Penerbit Kanisius. Yogyakarta.

Rukmana, R dan Y. Yuniarsih. 2000. Kedelai, Budidaya dan Pascapanen. Kanisius. Yogyakarta.

Salisbury, F.B. \& Cleon W.S. 1992. Fisiologi Tanaman jilid 2. Penerbit ITB. Bandung

Sinaga, R. 2009. Uji Efektivitas Pestisida Nabati terhadap Hama Spodoptera litura (Lepidoptera: Noctuidae) pada Tanaman Tembakau (Nicotiana tabaccum L.). FP Universitas Sumatera Utara. Medan. [Skripsi].

Suprapto. 1995. Bertanam Kedelai. Penebar Swadaya. Jakarta. Tarmadi, Dkk. 2007. Pengaruh Ekstrak bintaro (Carbera odollam Gaertn) Dan Kecubung (Brugmansia Candida Pers) Terhadap Rayap Tanah Coptotermes Sp. J. Tropical Wood Science and Technology Vol.5 - No.1.http://jurnalmapeki.biomaterial-lipi. org/jurnal/05012007/05012007-38-42.pdf.

Tohir, A.M. 2010. Teknik Ekstraksi Dan Aplikasi Beberapa Pestisida Nabati untuk Menurunkan Palatabilitas Ulat Grayak (Spodoptera Litura Fabr.) di Laboratorium. Buletin Teknik Pertanian Vol. 15, No. 1, 2010: 37-40. 